\title{
Processing and Mechanical Behavior of Banana Fibre Reinforced Epoxy based Composite with Alumina and silicon Carbide
}

\author{
Kaushal Arrawatia ${ }^{1}$, Kedar Narayan Bairwa ${ }^{2}$, Raj Kumar ${ }^{3}$ \\ ${ }^{*}$ Mechanical Engineering Department, RCERT, Jaipur, Rajasthan, India \\ ${ }^{2}$ Mechanical Engineering Department, RCERT, Jaipur, Rajasthan, India \\ ${ }^{3}$ Mechanical Engineering Department, Jaipur, India
}

\begin{abstract}
Article Info
Volume 8, Issue 6

Page Number : 434-441

\section{Publication Issue}

November-December-2021
\end{abstract}

\section{Article History}

Accepted : 05 Dec 2021

Published : 20 Dec 2021

\section{ABSTRACT}

Polymer composites have outstanding qualities such as high strength, flexibility, stiffness, and lightweight. Currently, research is being performed to develop innovative polymer composites that may be used in many operational situations and contain a variety of fibre and filler combinations. Banana fibre has low density compared to glass fibre and it is a lingo-cellulosic fibre having relatively good mechanical properties compared to glass fibre. Because of their outstanding qualities, banana fibre reinforced polymer composites are now widely used in various industries. The primary goal of this study is to determine the effect of the wt.\% of banana fibre, the wt.\% of SiC, and the wt.\% of $\mathrm{Al}_{2} \mathrm{O}_{3}$ in banana fibre reinforcement composites on the mechanical and physical properties of banana fibre reinforcement composites. Tensile strength and flexural strength of unfilled banana fibre epoxy composite increased with the increase in wt. of banana fibre from 0 wt.\% to 12 wt.\%. Further, an increase in wt.\% banana fibre drop in mechanical property was observed. It has been concluded from the study that the variation in percentage weight of filler material with fixed amount (12 wt.\%) of banana fibre affects the mechanical properties of filled banana reinforcement composites. Optimum mechanical properties were obtained for BHEC5 (72 wt.\% Epoxy + Hardener, 12 wt.\% banana fibre and $16 \mathrm{wt} . \% \mathrm{Al}_{2} \mathrm{O}_{3}$ ).

Keywords: Polymer composites, banana fibre, epoxy, $\mathrm{SiC}, \mathrm{Al}_{2} \mathrm{O}_{3}$, tensile strength, and flexural strength

\section{INTRODUCTION}

Nowadays, worldwide, researchers are going on to motivate, study and develop a new natural fibre reinforced polymer (NFRP) composite. Researchers are focusing on environmental awareness and the economic value of the different types of polymer composites. Recently, researchers are also focusing on geometrically rising crude oil costs get more significant global waste problems and more 
operation/processes prices. So that researchers are going on the concepts of sustainability and a reassessment of renewable resources kawade and Narve (2017). Researchers tempted NFRP composites as a research point because NFRP composites have several advantages over synthetic fibre reinforced composites such as an option for low cost, low density, locally available, ease of manufacturing, non-toxicity, good mechanical properties, good insulation property, good renewable, biodegradable, entirely or partially recyclable and environmentally friendly Singh et al. (2013); Chandole (2012).

Rout and Satapathy (2012) created the epoxy-GF/rice husk hybrid composite materials by adding rice husk at four weight percentages $(0,5,10$, and 15) and examined their mechanical properties. It has been discovered that by reinforcing the rice husk, the mechanical properties of the hybrid composites may be significantly improved. When rice husk is added to composite materials, the tensile and flexural strengths are reduced. Idicula et al. (2010) observed mechanical behavior of the banana, sisal and hybrid reinforced polyester composites. These aides deciding the layering examples and fibre piece and focus those are the elements of tensile properties of the composites. Neher et al. (2020) analysed the mechanical and physical characteristics of continuous aligned banana fibre orientation epoxy composite and continuous bidirectional banana fibre orientation epoxy composite. Authors noticed that epoxy composite with continuous aligned fibre orientation had better tensile strength and hardness as compared to epoxy composites with continuous bi-directional fibre orientation. Singh et al. (2011) examined banana fibre composite malleable properties because of the difference in the rate of the weight of silica powder. It indicated that expanding the modulus of flexibility and effect quality of composite by the expansion of silica. Hussain et al. (1996) investigated the mechanical characteristics of unidirectional carbon fibre reinforced epoxy composite and unidirectional carbon fibre reinforced epoxy composite with $\mathrm{Al}_{2} \mathrm{O}_{3}$ filler. Results revealed that hybridization of carbon fibre reinforced composite with nano and micro-sized $\mathrm{Al}_{2} \mathrm{O}_{3}$ give optimal mechanical properties. Basavarajappa et al. (2010) studied the influence of $\mathrm{SiC}$ as filler material on the three-body abrasive wear behavior of glass-epoxy composites was explored by taking into account the applied load, sliding speed, and abrading distance as abrasive wear variables. According to experimental results, wear increased with increasing applied load, sliding speed, and rubbing distance for both unfilled glass-epoxy composite and $\mathrm{SiC}$ filled glass-epoxy composite. Patnaik et al. (2010) studied the impact of filler materials such as silicon carbide ( $\mathrm{SiC})$, alumina $\left(\mathrm{Al}_{2} \mathrm{O}_{3}\right)$, and pine bark dust (PBD) on the three-body abrasive wear behavior of epoxy-based composites. $\mathrm{Al}_{2} \mathrm{O}_{3}$ and $\mathrm{PBD}$ filled random glass fibre-epoxy resin composites were shown to have superior wear resistance properties than $\mathrm{SiC}$ filled random glass fibre-epoxy resin composites, according to the findings of this study. Raju et al. (2012) studied the effect of silicon dioxide as a filler material on the twobody abrasive wear behavior of a silicon dioxide filled glass fabric reinforced epoxy composite by measuring its mechanical properties. The mechanical properties and wear resistance of silicon dioxide filled glass fabric reinforced epoxy composite were found to be superior to those of unfilled glass fabric reinforced epoxy composite. O.Asi (2008) examined the mechanical characteristics of a glass-fibre reinforced epoxy composite filled with varying quantities of $\mathrm{Al}_{2} \mathrm{O}_{3}$ particles in a glass fibre reinforced epoxy composite. An experimental analysis reveals that increasing $\mathrm{Al}_{2} \mathrm{O}_{3}$ particle content in epoxy composites causes the ultimate strength of glass fibre reinforced epoxy composites to degrade while increasing $\mathrm{Al}_{2} \mathrm{O}_{3}$ particle content causes the flexural strength first to increase and then decline. Petersan et al. (2015) experimented to check mechanical properties on fire resistant glass fibre reinforced polymer by using alumina tri hydrate as filler at various percentages. Adding Alumina tri hydrate decreases strength and 
increases brittleness of fibre reinforced polymer. Increasing filler content shows significant effect of stiffness and strength. This research work has analyzed and compared unfilled and $\mathrm{SiC}$ and $\mathrm{Al}_{2} \mathrm{O}_{3}$ filled banana fibre reinforced polymer composite under the tensile strength and flexural strength.

\section{METHODS AND MATERIAL}

\subsection{Material Selection}

Epoxy resin (LY 556), hardener (HY951), banana fibre, mold sheet, a heavy-duty silicone spray, alumina (200 mesh) and silicon carbide (200 mesh).

\subsubsection{Matrix Materials}

As corrosion resistance properties, mechanical properties, low shrinkage and chemical properties are way superior in the polymeric epoxy resin during curing, this is widely used in the formation of many polymer composites. So, for the fabrication of polymer composites, LY556 resin and HY 951 was chosen as the matrix material and hardener, respectively.

\subsubsection{Fibre Material}

Fibre is the reinforcing phase of composite material in general. Banana fibre is used as a natural fibre in an epoxy matrix to create some hybrid composites. As a result, nonwoven banana fibre was used to make composites for this study.

\subsubsection{Filler Material}

Silicon carbide and aluminum oxide are extremely favorable materials in fabricating composites as filler materials as they have high strength at elevated temperature, low thermal expansion, high thermal conductivity and chemical reaction reactive properties.

\subsection{Fabrication of Composites}

The production of the composite slabs is accomplished by using a traditional hand-lay-up approach followed by a gentle compression molding procedure. Firstly, we have prepared the wooden blocks ten in numbers. After that, thin plastic sheets (mold releasing sheets) are fixed at the bottom of the mold plate to get good surface finish of the product. Then after release gel silicon spray is sprayed on the surface of thin plastic sheets to avoid the sticking of polymer to the surface of thin plastic sheets. After this banana fibre is being chopped in a small size and weighted according to the ratio. These pieces of fibre then mixed with the epoxy resin and the hardener in a particular ratio. This procedure is done without silicon carbide and aluminum oxide till now. After properly mixing banana fibre and hardener in epoxy resin we poured this mixture on the already made wooden block. After that, releasing gel is sprayed on the inner surface of the plastic sheet. Then, this sheet is placed on the top layer of fibre and polymer. A roller is moved with a mild pressure on the plastic sheet to remove any air trapped as this mixture and leave of 24 hours. Then new composites with a different weight proportion of $\mathrm{SiC}$ and $\mathrm{Al} 2 \mathrm{O} 3$ particulates composite have been fabricated, as shown in Table 1

TABLE: 1

FABRICATION OF COMPOSITES REINFORCED

WITH VARYING WT.\% OF REINFORCEMENTS AND FILLERS

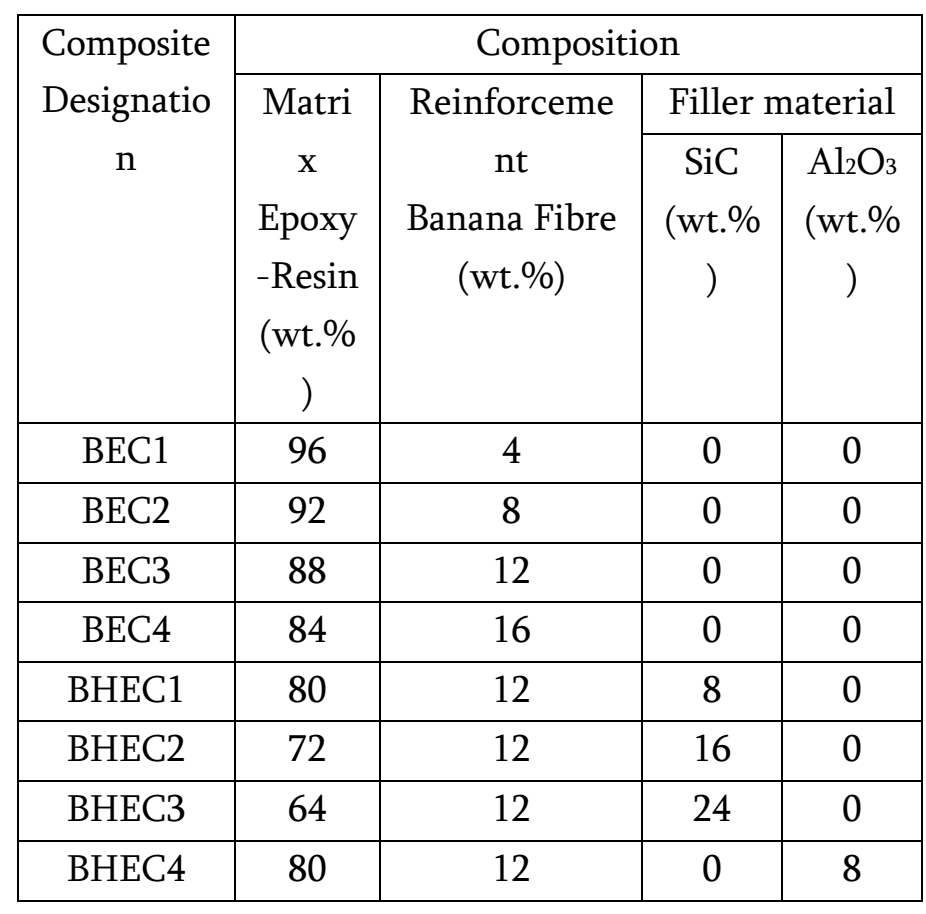




\begin{tabular}{|l|l|l|l|l|}
\hline BHEC5 & 72 & 12 & 0 & 16 \\
\hline BHEC6 & 64 & 12 & 0 & 24 \\
\hline
\end{tabular}

strength for that composite, as shown in table 3. It can be shown in figure 1 that the tensile strength of developed epoxy composites increases as the amount

After fabrication of the composites for physical and mechanical characterization, suitable-sized specimens were cut with a cutter as per ASTM standards for respective tests.

TABLE: 2

\section{SPECIMENS AS PER ASTM STANDARDS FOR MECHANICAL TESTING}

\begin{tabular}{|l|l|l|l|}
\hline S. No. & $\begin{array}{l}\text { Mechanical } \\
\text { Test }\end{array}$ & $\begin{array}{l}\text { Samples as per ASTM } \\
\text { standards }\end{array}$ \\
\hline 1. & Tensile Test & & \\
\hline 2. & $\begin{array}{l}\text { Flexural } \\
\text { Test }\end{array}$ & & \\
\hline
\end{tabular}

\section{III.RESULTS AND DISCUSSION [Page Style ]}

\subsection{Mechanical Testing of Developed Composites}

\subsubsection{Tensile Test}

The tensile test of the developed epoxy composites was performed using a universal testing machine (UTM Instron 1195) under ambient circumstances. According to the ASTM standard, the shape and size of specimens for the tensile test has designation (D3039-76).

TABLE: 3

TENSILE STRENGTH OF UNFILLED COMPOSITES

\begin{tabular}{|c|c|c|c|c|}
\hline Composite & \multirow{2}{*}{$\begin{array}{c}\text { Banana } \\
\text { Designation }\end{array}$} & \multicolumn{3}{|c|}{ Tensile Strength (MPa) } \\
\cline { 3 - 5 } & (wt.\%) & 1 & 2 & Mean \\
\hline BEC1 & 4 & 5.8 & 5.6 & 5.7 \\
\hline BEC2 & 8 & 6.7 & 6.3 & 6.5 \\
\hline BEC3 & 12 & 10.1 & 9.5 & 9.8 \\
\hline BEC4 & 16 & 7.0 & 7.2 & 7.1 \\
\hline
\end{tabular}

The tensile load applied at a crosshead speed of 0.5 $\mathrm{mm} / \mathrm{min}$. For all the fabricated composites, two identical specimens have been tested. The average of the tensile strength value has been taken as tensile of fibre loaded increases. For low weight \% of fibre loading (BEC1), tensile strength is low due to the less fibre interface area. Further increase in \% weight of fibre leads to an increase in fibre interface area, therefore increasing tensile strength (BEC3). Beyond the specific limit, further increase in fibre loading decreases tensile strength due to incomplete adhesion at the entire surface because of fibre-fibre interaction and improper wetting of fibre (BEC4). When comparing all of the unfilled banana fibre reinforcement composites manufactured, the composite with 12 percent fibre loading (BEC3) has shown the highest tensile strength.

\section{FIGURE: 1}

\section{COMPARISON OF TENSILE STRENGTH USING} DIFFERENT WT. \% OF BANANA FIBRE

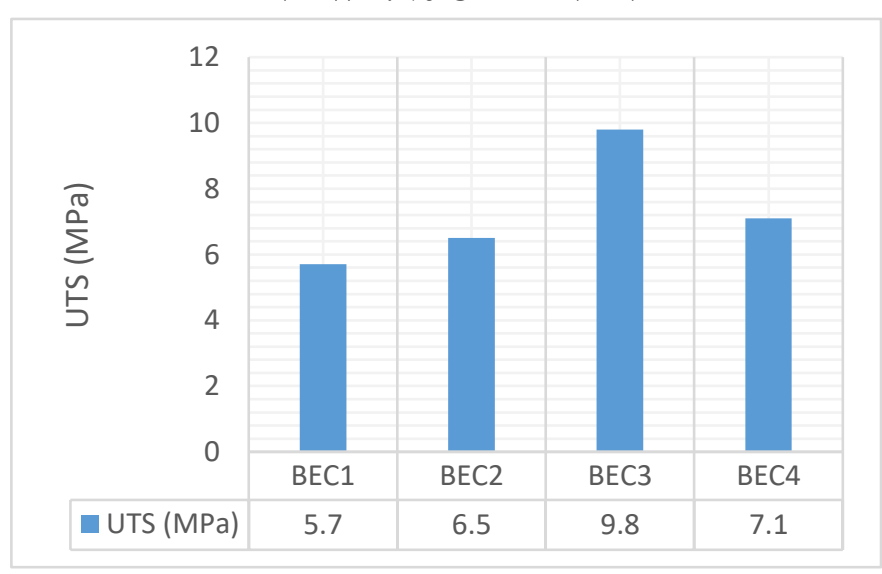

\subsubsection{Flexural Test}

The flexural test of the composite was carried out with the help of a universal testing equipment (UTM Instron 1195). The shape and size of specimens for flexural test has been fabricated according to the ASTM standard with designation (D2344-84).

The flexural load was applied at a crosshead speed of $0.5 \mathrm{~mm} / \mathrm{min}$. For all the fabricated composites, two identical specimens have been tested. The average of the flexural strength value has been taken as flexural strength for that composite as shown in table 4 . Figure 2 shows the bar chart for flexural strength of unfilled banana fibre composites. 
TABLE: 4

FLEXURAL STRENGTH OF UNFILLED

COMPOSITES

\begin{tabular}{|c|c|c|c|c|}
\hline Composite & \multirow{2}{*}{$\begin{array}{c}\text { Banana } \\
\text { Designation }\end{array}$} & \multicolumn{3}{|c|}{ Flexural Strength (MPa) } \\
\cline { 3 - 5 } & (wt.\%) & 1 & 2 & Mean \\
\hline BEC1 & 4 & 15.8 & 15.4 & 15.6 \\
\hline BEC2 & 8 & 19.3 & 18.9 & 19.1 \\
\hline BEC3 & 12 & 23.6 & 23.0 & 23.3 \\
\hline BEC4 & 16 & 21.0 & 20.8 & 20.9 \\
\hline
\end{tabular}

FIGURE: 2

COMPARISON OF FLEXURAL STRENGTH USING DIFFERENT WT. \% OF BANANA FIBRE

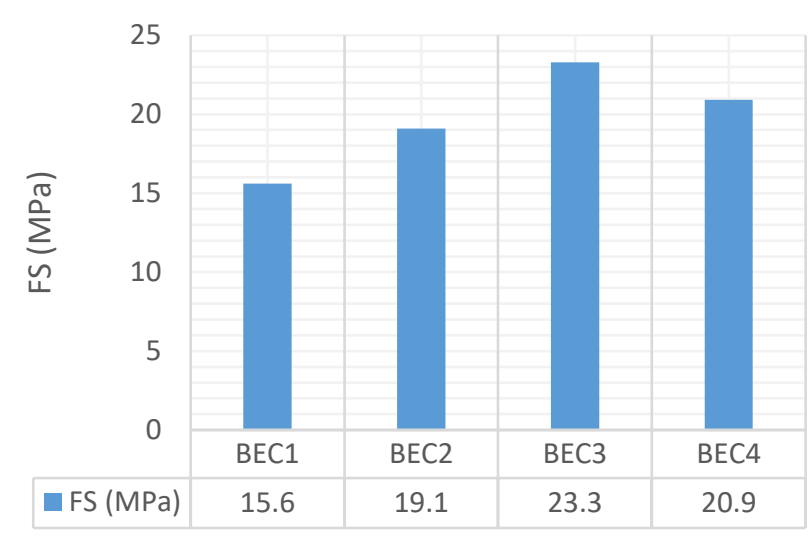

From figure 2, it can be seen that the value of flexural strength of fabricated composites first improves with an increase in fibre loading up to weight percent 12 (i.e., BEC1 to BEC3), after which the value decreases. The homogeneous distribution of fibres in composites rises with an increase in the percentage of fibres in the composite, which helps to prevent early sliding of the polymer phase. The stress transfer occurs near the fibres. The homogenous distribution of fibres in the composites causes fracture initiation and propagation to appear in multiple directions rather than in a single direction, increasing flexural strength by increasing flexural stiffness. Beyond the specific limit, further increase in fibre loading (BEC4) decreases flexural strength due to incomplete adhesion at the entire surface because of fibre-fibre interaction and improper wetting of fibre. The maximum flexural strength has been achieved with 12 wt.\% loading of fibre.

\subsection{Mechanical Behavior of Filled Particulate Banana Fibre Polymer Composites}

This section describes the mechanical testing and analysis of results obtains after mechanical testing.

\subsubsection{Tensile Strength}

For all the fabricated composites, two identical specimens have been tested on UTM. The average of the value of ultimate tensile strength has been taken as ultimate tensile strength for that composite as shown in table 5. Figure 3 indicates the tensile strength of fabricated composites.

TABLE: 5

\section{COMPARISON OF TENSILE STRENGTH USING DIFFERENT WT. \% OF SIC AND $\mathrm{Al}_{2} \mathrm{O}_{3}$}

\begin{tabular}{|c|c|c|c|}
\hline \multirow{2}{*}{$\begin{array}{c}\text { Composite } \\
\text { Designation }\end{array}$} & \multicolumn{3}{|c|}{ Ultimate Tensile Strength (UTS) (MPa) } \\
\cline { 2 - 4 } & UTS1 & UTS2 & UTS Mean \\
\hline BEC3 & 10.10 & 9.50 & 9.80 \\
\hline BHEC1 & 11.69 & 11.45 & 11.57 \\
\hline BHEC2 & 20.32 & 18.34 & 19.33 \\
\hline BHEC3 & 13.67 & 14.24 & 13.96 \\
\hline BHEC4 & 13.51 & 12.64 & 13.08 \\
\hline BHEC5 & 19.23 & 19.86 & 19.55 \\
\hline BHEC6 & 16.42 & 15.92 & 16.17 \\
\hline
\end{tabular}

FIGURE: 3

COMPARISON OF TENSILE STRENGTH USING DIFFERENT WT. \% OF SiC AND $\mathrm{Al}_{2} \mathrm{O}_{3}$

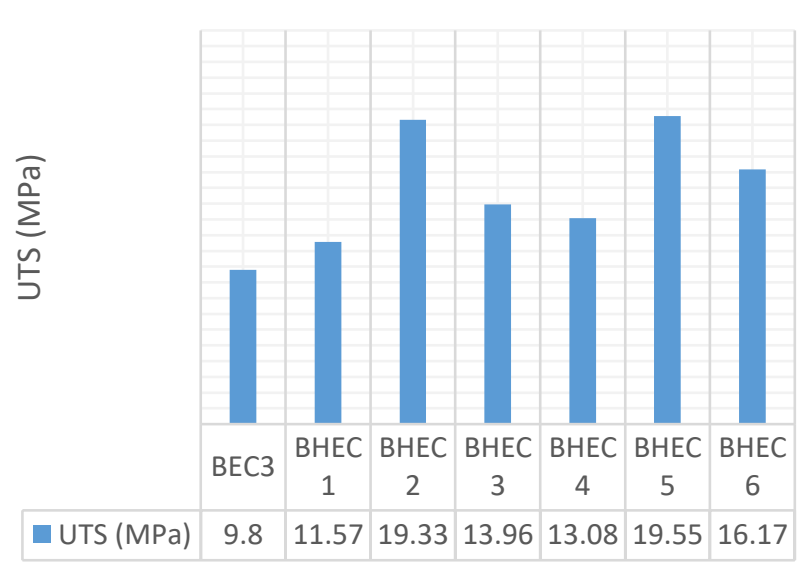


It has been exposed from the figure 3 that the value of tensile strength of composites initially increases with increase either $\mathrm{SiC}$ or $\mathrm{Al}_{2} \mathrm{O}_{3}$ filler up to $16 \%$ wt. This is because filler particles act as a barrier in transferring stress from one point to another. Also, filler particulates increase the area for the bonding between the three different constituents of composites. Further addition of filler particulates from $16 \mathrm{wt} . \%$ in the composites reduces the tensile strength. It is due to an increase in more surface area and less matrix material for bonding. Due to insufficient bonding between three different constituents, the loads may not effectively be transferred from one end to another. Hence, there is a reduction in the tensile strength of the composite. The maximum tensile strength (19.55 $\mathrm{MPa}$ ) was achieved with 16 wt.\% filling of filler material (BHEC5).

\subsubsection{Flexural Strength}

For all the fabricated composites, two identical specimens have been tested. The average of the flexural strength value has been taken as flexural strength for that composite, as shown in table 6 . Figure 4 shows the bar chart of flexural strength of fabricated composites.

TABLE: 6

COMPARISON OF FLEXURAL STRENGTH USING DIFFERENT WT. \% OF SiC AND $\mathrm{Al}_{2} \mathrm{O}_{3}$

\begin{tabular}{|c|c|c|c|}
\hline \multirow{2}{*}{$\begin{array}{c}\text { Composite } \\
\text { Designation }\end{array}$} & \multicolumn{3}{|c|}{ Flexural Strength (FS) (MPa) } \\
\cline { 2 - 4 } & FS1 & FS2 & FS Mean \\
\hline BEC3 & 23.60 & 23.00 & 23.30 \\
\hline BHEC1 & 22.38 & 21.48 & 21.93 \\
\hline BHEC2 & 46.53 & 46.67 & 46.60 \\
\hline BHEC3 & 39.72 & 38.93 & 39.33 \\
\hline BHEC4 & 24.34 & 25.73 & 25.04 \\
\hline BHEC5 & 49.23 & 49.78 & 49.51 \\
\hline BHEC6 & 42.54 & 41.87 & 42.21 \\
\hline
\end{tabular}

It has been observed from the figure 4 that the value of flexural strength of fabricated composites initially increases with increase either in wt.\% of $\mathrm{SiC}$ or wt.\% of $\mathrm{Al}_{2} \mathrm{O}_{3}$ up to $16 \mathrm{wt} . \%$ It is due to an increase in bonding surface area between fibre, filler epoxy matrix. The figure also revealed that further addition of filler material above $16 \mathrm{wt} . \%$ decreases the flexural strength of fabricated composites. It is due to incomplete adhesion at the entire surface because of improper wetting of fibre, hence improper interfacial bonding between the alumina particles, fibre and epoxy matrix. The maximum flexural strength has been obtained for BHEC5 with 16 wt.\% loading of $\mathrm{Al}_{2} \mathrm{O}_{3}$ particulates.

FIGURE: 4

\section{COMPARISON OF FLEXURAL STRENGTH} USING DIFFERENT WT. \% OF SiC AND $\mathrm{Al}_{2} \mathrm{O}_{3}$

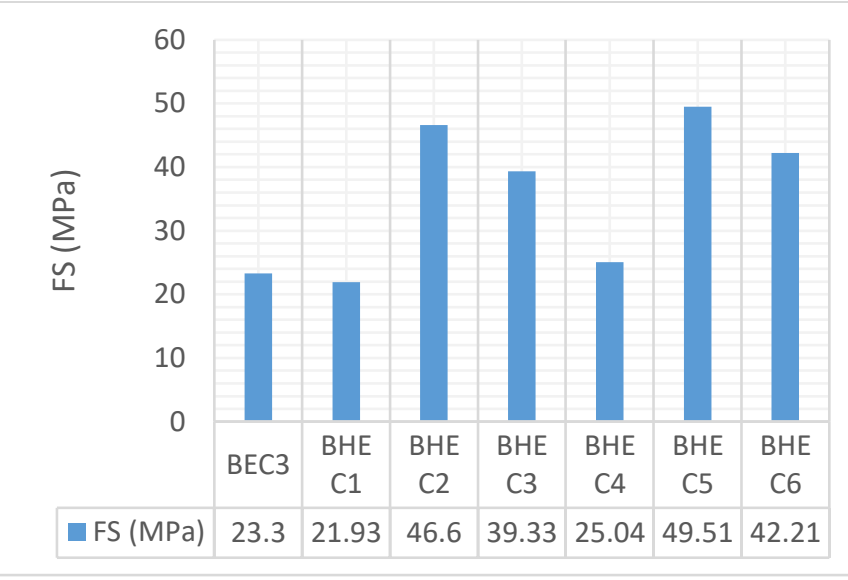

From the analysis of figure 3 and 4 it was revealed that $\mathrm{SiC}$ or $\mathrm{Al}_{2} \mathrm{O}_{3}$ filled banana reinforcement composites exhibited superior mechanical properties than unfilled banana reinforcement composites. On the other hand, it was also shown that impact strength, flexural strength, tensile strength initially increases with increased wt.\% of filler particles from $0 \%$ weight to $16 \%$ weight. Further, rise in filler particles from 16 wt.\% to 24 wt.\% decreases the impact strength, flexural strength, tensile strength of banana fibre composites. The maximum impact strength, flexural strength, tensile strength is achieved with $16 \%$ wt. of $\mathrm{Al}_{2} \mathrm{O}_{3}$ filler (BHEC5). The hardness of the $\mathrm{SiC}$ or $\mathrm{Al}_{2} \mathrm{O}_{3}$ filled banana fibre reinforcement composites continuously increases 
with an increase in filler from $0 \%$ wt. to $24 \%$ wt. in the composites. The maximum hardness is achieved with $24 \%$ wt. of $\mathrm{Al}_{2} \mathrm{O}_{3}$ filler (BHEC6).

\section{CONCLUSION}

The present work is focused on investigating the effect of fibre loading and \% wt. of filler content on mechanical and Physical behavior of banana fibre reinforced epoxy composites. The following conclusions were obtained from the current study:

$>$ The variation in percentage weight of banana fibre affects the mechanical properties (tensile strength and flexural strength) of unfilled banana reinforcement composites.

$>$ The flexural strength, and tensile strength increase with fibre loading from 4 wt. \% to 12 wt. \%. Further increase in banana fibre loading beyond $12 \mathrm{wt} . \%$ leads to decreased in flexural strength and tensile strength.

$>$ The BEC3 shows the maximum flexural strength, and tensile strength of fabricated unfilled banana reinforcement composites.

$>$ Initially flexural strength and tensile strength increase with increase in \% wt. of filler material from $0 \%$ weight to $16 \%$ weight. Further increase in filler particles from $16 \%$ wt. to $24 \%$ wt. decreases the flexural strength, and tensile strength of banana fibre composites.

$>$ The maximum flexural strength and tensile strength is achieved with $16 \%$ wt. of Al2O3 filler (BHEC5).

\section{REFERENCES}

[1] H. M. Kawade and N. G. Narve, "Natural Fibre Reinforced Polymer Composites: A Review", International Journal for Scientific Research and Development, vol. 5, no. 09, pp. 445-449, 2017.

[2] A. Singh, S. Singh and A. Kumar, "Study of Mechanical Properties and Absorption
Behaviour of Coconut Shell Powder-Epoxy Composites", International Journal of Materials Science and Applications, vol. 2, no. 5, pp. 157$161,2013$.

[3] P. Chandole, "Mechanical and Tribological Behaviour of Coconut Shell Char Reinforced Polymer Composites", 2012.

[4] A. K. Rout and A. Satapathy, "Study on Mechanical and Tribo-Performance of RiceHusk Filled Glass-Epoxy Hybrid Composites," Materials and Design, vol. 41, pp. 131-14, 2012.

[5] M. Idicula, K. Joseph and S. Thomas, "Mechanical Performance of Short Banana/Sisal Hybrid Fibre Reinforced Polyester Composites", Journal of Reinforced Plastic and Composite, vol. 29, pp. 12-29, 2010.

[6] B. Neher, R. Hossain, K. Fatima, M. A. Gafur, M. A. Hussain and F. Ahmed, "Study of the Physical, Mechanical and Thermal Properties of Banana Fibre Reinforced HDPE Composites", Materials Sciences and Applications, vol. 11, pp. 245-262, 2020.

[7] V. K. Singh, P. C. Gope, S. Chauhan and D. S. Bisht "Mechanical Behavior of Banana Fibre Based Hybrid Bio Composites", Journal of Material Environment Science, vol. 3, no.1, pp. 185-194, 2011.

[8] M. Hussain, A. Nakahira and K. Niihara, "Mechanical Property Improvement of Carbon Fibre Reinforced Epoxy Composites by $\mathrm{Al}_{2} \mathrm{O}_{3}$ Filler Dispersion," Materials Letters, pp. 185191, 1996.

[9] S. Basavarajappa, A. G. Joshi, K. V. Arun, A. P. Kumar and M. P. Kumar (2010), "Three-Body Abrasive Wear Behaviour of Polymer Matrix Composites Filled with SiC Particles," PolymerPlastics Technology and Engineering, vol. 49, no. 1, pp. 8-12, 2010.

[10] A. Patnaik, A. Satapathy and S. Biswas, "Investigations on Three-Body Abrasive Wear and Mechanical Properties of Particulate Filled 
Glass Epoxy Composites," Malaysian Polymer

Journal, vol. 5, no. 2, pp. 37-48, 2010.

[11] B. R. Raju, B. Suresha and R. P. Swamy (2012), "Tribo-Performance of Silicon Dioxide Filled Glass Fabric Reinforced Epoxy Composites," $A R P N$ Journal of Engineering and Applied Sciences, vol. 7, 2012.

[12] O. Asi, "Mechanical properties of glass fibre reinforced epoxy composites filled withAl2O3 Particles," Journal of Reinforced Plastics and Composites, vol. 28, no. 23, pp. 2861-2867, 2008.

[13] M. R. Petersen, A. Chen, M. Roll, S. Jang and M. Yossef, "Mechanical Properties of FireRetardant Glass Fibre Reinforced Polymer Materials with Alumina Tri-Hydrate Filler," Composites Part B, vol. 78, pp. 109-121, 2015.

\section{Cite this article as :}

Kaushal Arrawatia, Kedar Narayan Bairwa, Raj Kumar, "Processing and Mechanical Behavior of Banana Fibre Reinforced Epoxy based Composite with Alumina and silicon Carbide", International Journal of Scientific Research in Science and Technology (IJSRST), Online ISSN : 2395-602X, Print ISSN : 2395-6011, Volume 8 Issue 6, pp. 434-441, November-December 2021. Available

doi : https://doi.org/10.32628/IJSRST218661

Journal URL : https://ijsrst.com/IJSRST218661 